\title{
Effects of Perinatal Stress and Drug Abuse on Maternal Behavior and Sensorimotor Development of Affected Progeny
}

\author{
A. HOLUBOVÁ ${ }^{1}$, M. ŠEVČÍKOVÁ ${ }^{1}$, E. MACÚCHOVÁ ${ }^{1}$, I. HREBÍČKOVÁ $^{1}$, \\ M. POMETLOVÁ ${ }^{1}$, R. ŠLAMBEROVÁ ${ }^{1}$
}

${ }^{1}$ Department of Normal, Pathological and Clinical Physiology, Third Faculty of Medicine, Charles University, Prague, Czech Republic

Received March 23, 2017

Accepted October 25, 2017

\begin{abstract}
Summary
Methamphetamine (MA) is an addictive psychostimulant with significant potential for abuse. Previous rat studies have demonstrated that MA use during pregnancy impairs maternal behavior and induced delayed development of affected pups. The offspring of drug-addictive mothers were often neglected and exposed to neonatal stressors. The present study therefore examines the effect of perinatal stressors combined with exposure to prenatal MA on the development of pups and maternal behavior. Dams were divided into three groups according to drug treatment during pregnancy: controls (C); saline (SA, s.c., $1 \mathrm{ml} / \mathrm{kg}$ ); MA (s.C., $5 \mathrm{mg} / \mathrm{ml} / \mathrm{kg}$ ). Litters were divided into four groups according to postnatal stressors: controls $(\mathrm{N})$; maternal separation (S); maternal cold-water stress (W); maternal separation plus cold-water stress (SW). The pup-retrieval test showed differences among postnatally stressed mothers and non-stressed controls. The righting reflex on a surface revealed delayed development of pups prenatally exposed to MA/SA and postnatal stress. Negative geotaxis and Rotarod results confirmed that the MA group was the most affected. Overall, our data suggests that a combination of perinatal stress and prenatal MA can have a detrimental effect on maternal behavior as well as on the sensorimotor development of pups. However, MA exposure during pregnancy seems to be the decisive factor for impairment.
\end{abstract}

\section{Key words}

Methamphetamine - Maternal separation - Cold water • Development • Maternal behavior

\section{Corresponding author}

R. Šlamberová, Department of Normal, Pathological and Clinical
Physiology, Third Faculty of Medicine, Charles University, Ke Karlovu 4, 12000 Prague 2, Czech Republic. Fax: +420 224902 750. E-mail: romana.slamberova@lf3.cuni.cz

\section{Introduction}

Methamphetamine (MA) is a very popular, widely used drug in many countries. Statistics show that a high percent of drug addicted women switch to MA after becoming pregnant (Marwick 2000, Šlamberová et al. 2006). A possible explanation lies in the effects of this powerful psychostimulant and its significant potential for abuse due to feelings of increased energy, euphoria, and suppressed appetite (Marwick 2000, Šlamberová et al. 2006, Kish 2008). Since MA easily crosses the placental barrier the development of affected fetuses can be impaired (Rokyta et al. 2008, Rambousek et al. 2014). A number of previous studies have demonstrated that prenatal application of MA induces delayed sensorimotor development of rat pups (Martin 1975, Acuff-Smith et al. 1996, Šlamberová et al. 2006, Šlamberová 2012). Clinical studies have demonstrated decreased weight, length, and head circumference of neonates born to mothers who abused MA during pregnancy (Oro and Dixon 1987, Little et al. 1988). MA exposure is significantly associated with poor suckling and breastfeeding, reduced sleeping and alertness, less coordinated movements, and increased stress in children (Oro and Dixon 1987, Little et al. 1988, Smith et al. 2015). Moreover, maternal use of MA has also been associated with increased maternal depressive symptoms and parenting stress (Liles et al. 2012). Thus, the 
offspring of drug-addictive mothers are often neglected and exposed to neonatal stressors (Larsson et al. 1979, Šlamberová et al. 2005a, Rokyta et al. 2008).

Early life experiences, such as child neglect and maternal separation, are associated with impaired neurological development and may lead to various pathologies in adulthood (Daniels et al. 2004, Marais et al. 2008, Lajud et al. 2012). Maternal separation is an animal model that simulates the effects of early life experiences on the hypothalamo-pituitary-adrenal (HPA) axis and behavioral responses (Daniels et al. 2004, Marais et al. 2008, Lajud et al. 2012). Periodic maternal separation is a potent social stressor that can impact and activate the HPA axis response in pups even during the hypo-responsive period (SHRP) that occurs during the first two postnatal weeks (Sapolsky and Meaney 1986, Lajud et al. 2012). Such exposure to neonatal stress can produce long-term increases in the responsiveness of the HPA axis as well as anxiety, depression, and drug abuse in adulthood (Ladd et al. 1996, Daniels et al. 2004, Plotsky et al. 2005). Stressors are usually subdivided to social and physical, with most stressors studied in animals being a mixture of both (Grissom and Bhatnagar 2009). In the present study, rats were exposed to (1) a social stressor represented by maternal separation, (2) a physical stressor represented by maternal cold-water stress (Drago et al. 1999, Šlamberová et al. 2002), or (3) a combination of the two stressors.

Our previous studies have shown that repeated injection during pregnancy, regardless of substance (MA or saline (SA)), induces long-term impairment of stress responsiveness in adult offspring (Peters 1986, Šlamberová et al. 2002). Moreover, during pregnancy, there is a naturally elevated level of cortisol, which is essential for fetal growth (Charil et al. 2010). Stress during pregnancy increases the mother's own circulating cortisol and reduces the expression and activity of the glucocorticoid barrier enzyme in the placenta, leaving the fetus less protected (Welberg et al. 2005). Injections can, therefore, play the role of a prenatal stressor that can affect the development of pups. In our study, this form of prenatal stress was evaluated through the SA-injected/exposed groups.

The present study examines the effect of perinatal maternal stressors combined with exposure to prenatal MA $(5 \mathrm{mg} / \mathrm{ml} / \mathrm{kg})$ on maternal behavior and development of affected pups. Our working hypothesis was that (1) perinatal stress amplifies the detrimental effects of MA on maternal behavior and (2) this effects the morphological and functional development of offspring. The experimental protocol was derived from our earlier studies (Šlamberová et al. 2005a, Šlamberová et al. 2006, Pometlová et al. 2009, Malinová-Ševčíková et al. 2014).

\section{Methods}

\section{Prenatal care}

Ninety-six nulliparous adult female, albino Wistar rats (250-300 g) were delivered by Velaz (Prague, Czech Republic) from Charles River Laboratories International, Inc. Females were housed in groups (4 per cage) and left undisturbed for one week in a temperaturecontrolled $\left(22-24{ }^{\circ} \mathrm{C}\right)$ colony room, with food and water ad libitum, on a $12 \mathrm{~h}$ light cycle (lights on at 6:00 am). After one week of acclimatization, females were housed overnight with mature males (Šlamberová et al. 2006). Dams were then randomly assigned to those, who would receive (1) MA (s.c., $1 \mathrm{mg} / \mathrm{ml} / \mathrm{kg}$ ), (2) $\mathrm{SA}(1 \mathrm{ml} / \mathrm{kg}$ ), or (3) no drugs/injections ( $C$, controls), during the entire period of gravidity. All females were weighted daily to determine if MA affected weight. On day 20 of gestation, females were placed into maternity cages (1 per cage). The day of delivery was counted as postnatal day (PD) 0 .

\section{Postnatal care}

On PD 1, litter size was adjusted to 12 pups and the pups were cross-fostered, so that one mother raised 4 pups from MA, 4 pups from SA, and 4 pups from control mothers. For recognition, prenatally MA-exposed pups were intradermally injected with black India ink in the left hind paw, SA-exposed pups in right hind paw; controls were not tattooed. Whenever possible, equal numbers of males and females were raised by each mother. Stress-exposure was conducted once daily, starting on PD 1, until they were weaned on PD 21. Litters were then divided into four groups: controls $(\mathrm{N})$, maternal separation (S), maternal cold-water stress (W), and maternal separation plus maternal cold-water stress (SW).

\section{Social stress}

Maternal separation, as a social stressor, was conducted from PD 1-21, for $3 \mathrm{~h}$ per day, between 10:00-13:00 am (Plotsky et al. 2005, Lajud et al. 2012, Holubová et al. 2016). All pups (from appropriate groups $\mathrm{S}$ and $\mathrm{SW}$ ) were gently removed from their maternity cage and placed in separate cage in other room for $3 \mathrm{~h}$. The cage with pups was always placed on a heating pad 
to maintain normal body temperature.

\section{Physical stress}

Maternal cold-water stress was used as a physical stressor (Drago et al. 1999, Šlamberová et al. 2002). A plastic container ( $25 \times 35 \times 40 \mathrm{~cm}, \mathrm{LWH})$ was filled with $5^{\circ} \mathrm{C}$ water to a depth of $25 \mathrm{~cm}$. Each rat-mother (from appropriate groups $\mathrm{W}$ and $\mathrm{SW}$ ) was placed in the cold water and forced to swim for $5 \mathrm{~min}$. Rats were then towel-dried and placed under a heating lamp until they were mostly dry and then returned to their home cages. The water in the containers was cleaned of released feces after each animal.

\section{Litter characteristics}

On PD 1, number of pups and percentage of males and females in each litter was counted and the birth weight was also measured. Weight gain of pups was recorded during the entire lactation period from PD 1 to PD 21. The number of pups in each litter, the percentage of males and females and birth weights were analyzed using a two-way ANOVA (Drug $x$ Sex). A three-way ANOVA (Drug $x$ Postnatal stress $x$ Sex) was used to analyze the weight gain of pups. Bonferroni's test was used for post hoc test comparisons. Differences were considered significant if $\mathrm{p}<0.05$.

\section{Maternal behavior}

For this tests, we used the same protocol as that described by Šlamberová et al. 2005a and MalinováŠevčíková et al. 2014.

\section{Observational test}

Maternal behavior was observed daily for $50 \mathrm{~min}$ (between 08:00-09:00 am) in the home cage of each mother and her litter between PD 1 and PD 21. During each session, each mother and her litter were observed 10 times for $5 \mathrm{~s}$ at $5 \mathrm{~min}$ intervals. Eleven types of activities, exhibited by the mothers, and three variations of nursing positions were recorded during each session (Table 1). Thus, each mother and litter was observed 210 times (21 days x 10 observations per day). A two-way ANOVA (Drug x Postnatal stress) with Repeated Measure (Days) was used to analyze each maternal activity. Bonferroni's test was used for post hoc test comparisons. Differences were considered significant if $\mathrm{p}<0.05$.

Table 1. Effect of prenatal and postnatal treatment on maternal behavior compared to a non-stressed control group.

\begin{tabular}{|c|c|c|c|c|c|c|c|c|c|}
\hline & \multicolumn{3}{|c|}{$\mathbf{S}$} & \multicolumn{3}{|c|}{$\mathbf{W}$} & \multicolumn{3}{|c|}{ SW } \\
\hline & Control & Saline & MA & Control & Saline & MA & Control & Saline & MA \\
\hline $\begin{array}{l}\text { Active arched } \\
\text { position }\end{array}$ & 0 & 0 & 0 & 0 & 0 & 0 & 0 & 0 & 0 \\
\hline $\begin{array}{l}\text { Active blanket } \\
\text { position }\end{array}$ & 0 & 0 & 0 & 0 & 0 & 0 & 0 & 0 & 0 \\
\hline Passive nursing & $\uparrow$ & $\uparrow$ & $\uparrow$ & $\uparrow$ & $\uparrow$ & $\uparrow$ & $\uparrow$ & $\uparrow$ & $\uparrow$ \\
\hline In the nest & 0 & 0 & 0 & 0 & 0 & 0 & 0 & 0 & 0 \\
\hline In contact with pups & $\uparrow$ & $\uparrow$ & $\uparrow$ & $\uparrow$ & $\uparrow$ & $\uparrow$ & $\uparrow$ & $\uparrow$ & $\uparrow$ \\
\hline Grooming pups & 0 & 0 & 0 & 0 & 0 & 0 & 0 & 0 & 0 \\
\hline Carrying pups & NA & NA & NA & NA & NA & NA & NA & NA & NA \\
\hline $\begin{array}{l}\text { Manipulating nest } \\
\text { shaving }\end{array}$ & 0 & 0 & 0 & 0 & 0 & 0 & 0 & 0 & 0 \\
\hline Self-grooming & 0 & 0 & 0 & 0 & 0 & 0 & 0 & 0 & 0 \\
\hline Eating & 0 & 0 & 0 & 0 & 0 & 0 & 0 & 0 & 0 \\
\hline Drinking & 0 & 0 & 0 & 0 & 0 & 0 & 0 & 0 & 0 \\
\hline $\begin{array}{l}\text { Resting with eyes } \\
\text { closed }\end{array}$ & $\uparrow$ & 0 & 0 & $\uparrow$ & 0 & 0 & $\uparrow$ & 0 & 0 \\
\hline Rearing & 0 & 0 & 0 & 0 & 0 & 0 & 0 & 0 & 0 \\
\hline Sniffing & 0 & 0 & 0 & 0 & 0 & 0 & 0 & 0 & 0 \\
\hline
\end{tabular}

Values are means $\pm \mathrm{SEM}$. MA = methamphetamine; $\mathrm{S}=$ maternal separation; $\mathrm{W}=$ maternal cold-water stress; $\mathrm{SW}=\mathrm{combined}$ stressor. $\uparrow=$ increase in activity; $\downarrow=$ decrease in activity; $0=$ no effect; all compared to non-stressed control group (N). 


\section{Retrieval test}

The retrieval test was performed immediately after the observational test. The test was conducted daily PD 1-12 between 09:00-10:00 am. Each mother and litter was tested 12 times. All pups were removed from their mothers and placed in a separate cage for $5 \mathrm{~min}$. The cage with pups was placed on a heating pad to maintain body temperature. After separation, the entire litter was returned to their mother's cage, with the pups scattered around the cage. The mother was then observed for $10 \mathrm{~min}$ and the following latencies were measured: 1) time to carry the first pup, 2) time to return the first pup to the nest, and 3) time to return all pups to the nest. Latencies were analyzed using a two-way ANOVA (Drug $x$ Postnatal stress) with Repeated Measure (Days). Bonferroni's test was used for post hoc test comparisons. Differences were considered significant if $\mathrm{p}<0.05$.

\section{Battery of tests of the pups' development}

For this tests, we used the same protocol as that described by Altman and Sudarshan 1975, Šlamberová et al. 2006, and Malinová-Ševčíková et al. 2014.

\section{Righting reflex on a surface}

The righting reflex on a surface was tested daily (PD 1-12) after exposure of postnatal stressors. Each pup was placed on their back and the time it took for the pup to right itself with all four paws on the surface of the testing table was recorded. Times were tested using a three-way ANOVA (Drug $x$ Postnatal stress $x$ Sex) with Repeated Measure (Days). Bonferroni's test was used for post hoc test comparisons. Differences were considered significant if $\mathrm{p}<0.05$.

\section{Negative geotaxis}

Negative geotaxis was tested on PD 9. Each pup was placed facing downward on a screen-surface that was tilted at a $30^{\circ}$ angle from the horizontal. Each animal was given three trials and the best latency for turning and facing upward was recorded. Latencies were tested using a three-way ANOVA (Drug x Postnatal stress $x$ Sex). Bonferroni's test was used for post hoc test comparisons. Differences were considered significant if $\mathrm{p}<0.05$.

\section{Righting reflex in mid-air}

The righting reflex, in mid-air, was tested on PD 17. Each pup was held, ventral side up, $40 \mathrm{~cm}$ above a soft pad, then released and its orientation on contacting the soft pad was observed. A score of "1" was given, when the pup contacted the pad with all four paws or " 0 ", for all other orientations. The $\chi^{2}$ test was used to analyze differences in the righting reflex. Differences were considered significant if $\mathrm{p}<0.05$.

\section{Bar-holding test}

The bar-holding test took place on PD 23, and was used to examine vestibular function and sensorimotor coordination involved in the maintenance of balance on a narrow beam. A $40-\mathrm{cm}$ long beam, with a diameter of $1 \mathrm{~cm}$, was suspended $80 \mathrm{~cm}$ above a soft surface. The pup was placed on the beam, held by the nape of its neck and its forepaws were allowed to touch the beam. Time of the forepaw / hind paw grasping reflex was recorded with a limit of $120 \mathrm{~s}$. Three consecutive trials were conducted. Times were tested using a three-way ANOVA (Drug $x$ Postnatal stress $x$ Sex) with Repeated Measure (Trials). Bonferroni's post hoc test was used for analysis of ANOVA results. Differences were considered significant if $\mathrm{p}<0.05$.

\section{Rotarod}

Rotarod performance was examined on PD 23 to test sensorimotor coordination and dynamic postural reactions necessary to maintain the balance on a rotating cylinder. Pups were placed on a cylinder with a textured surface $(11.5 \mathrm{~cm}$ in diameter, rotating at a constant speed of $6 \mathrm{rpm}$ ) facing in the opposite direction of cylinder rotation, so that walking forward was needed to maintain position. The duration of balance on the rotarod was determined for $120 \mathrm{~s}$. Durations were assessed using a three-way ANOVA (Drug $x$ Postnatal stress $x$ Sex) with Repeated Measure (Trials). Bonferroni's post hoc test was used for comparisons. Differences were considered significant if $\mathrm{p}<0.05$.

\section{Results}

\section{Litter characteristics and maturation of the pups}

The birth weight in prenatally MA- $\left[F_{(2,352)}=\right.$ 53.69; $<<0.001]$ and SA-exposed $\left[F_{(2,352)}=53.69 ; \mathrm{p}<0.05\right]$ pups was lower than controls regardless of sex (Table 2). Moreover, MA-exposed pups were significant lighter than the SA-exposed $\left[F_{(2,352)}=53.69 ; \mathrm{p}<0.001\right]$. There were no significant differences in gestation length for any group. The number of pups per litter was also not significantly different among groups. The distribution of males and females in the litters was similar, thus, there were no differences between number of males and females among groups. 
Table 2. Effect of prenatal and postnatal treatment on pup weight.

\begin{tabular}{|c|c|c|c|}
\hline Prenatal treatment & Postnatal treatment & Birth weight & Weight gain \\
\hline \multirow{4}{*}{ Control } & $\mathrm{N}$ & \multirow{4}{*}{$6.95 \pm 0.06$} & $39.22 \pm 0.86$ \\
\hline & $\mathrm{S}$ & & $43.58 \pm 0.71^{* *}$ \\
\hline & $\mathrm{W}$ & & $41.50 \pm 0.69^{\#}$ \\
\hline & SW & & $39.35 \pm 0.76^{\#}$ \\
\hline \multirow{4}{*}{ Saline } & $\mathrm{N}$ & \multirow{4}{*}{$6.73 \pm 0.06^{*}$} & $41.98 \pm 0.97$ \\
\hline & $\mathrm{S}$ & & $42.95 \pm 0.72$ \\
\hline & $\mathrm{W}$ & & $40.38 \pm 0.69^{\#}$ \\
\hline & SW & & $37.44 \pm 0.76^{\#}$ \\
\hline \multirow{4}{*}{$M A$} & $\mathrm{~N}$ & \multirow{4}{*}{$6.07 \pm 0.06^{* * * \# \#}$} & $39.65 \pm 0.90$ \\
\hline & S & & $42.17 \pm 0.73$ \\
\hline & $\mathrm{W}$ & & $40.41 \pm 0.70$ \\
\hline & SW & & $37.40 \pm 0.76^{\#}$ \\
\hline
\end{tabular}

Values are means $\pm \mathrm{SEM} . \mathrm{N}=$ postnatally non-stressed group; $\mathrm{S}=$ maternal separation; $\mathrm{W}=$ maternal cold-water stress; $\mathrm{SW}=$ combined stressor. $* \mathrm{p}<0.05 ; * * \mathrm{p}<0.01$ significant difference between affected group and controls $(\mathrm{N})$. ${ }^{*} \mathrm{p}<0.05$ significant difference between $\mathrm{S}$ and other postnatal groups (W, SW).

\section{Maternal behavior}

Observation test

Nursing

As shown in Table 1, there were no differences in the active nursing positions among groups of mothers. However, the groups exposed to stress during lactation (i.e. S, W and SW groups) there was a significant increased passive nursing $\left[F_{(3,82)}=19.28 ; \quad \mathrm{p}<0.01\right]$ compared to $\mathrm{N}$ group. Both types of active nursing, arched and blanket position, decreased whereas passive nursing increased as the postpartum period progressed, regardless of drug treatment or exposure of stressors.

\section{Maternal activities}

MA-treated mothers groomed their pups less than SA groups $\left[F_{(2,79)}=4.00 ; \mathrm{p}<0.05\right]$ or $\mathrm{C}\left[F_{(2,79)}=4.00\right.$; $\mathrm{p}<0.05]$ during the lactation period, regardless of stress. There were no significant changes in terms of staying in the nest or manipulating the shavings during the sessions. Dams stressed during the lactation period had more contact with their pups $\left[F_{(3,80)}=7.46 ; \mathrm{p}<0.05\right]$ (Table 1). Additionally, all mothers - regardless of their drug or stress treatment - spent less time in the nest and had less contact with their pups (e.g. grooming) as the postpartum period progressed. Occurrences of the mother carrying the pups were too few for statistical analysis.

\section{Nonmaternal activities}

The non-stressed mothers (N) spent less time resting with their eyes closed $\left[F_{(3,82)}=13.40 ; \mathrm{p}<0.001\right]$ compared to dams exposed to stressors during lactation with respect to prenatal treatment. This effect was observed only in the control group $\mathrm{C}$, i.e. without prenatal treatment $\left[F_{(2,82)}=3.32 ; \mathrm{p}<0.05\right]$ (Table 1$)$. There were no changes in any of the other self-care activities, i.e. eating, drinking, or self-grooming. As the postpartum period progressed, and regardless of treatment, mothers exhibited more eating, drinking, and sleeping. Selfgrooming in all rats fluctuated during postpartum, and was highest during the first half of the lactation period. There were no changes in sniffing or rearing among the groups.

\section{Retrieval test}

Stress and drug treatment affected the latency involved in returning all pups to the nest. Specifically, all types of stressors during the lactation period decreased the latency to return all pups to the nest but only in the prenatal control group, i.e. $\mathrm{S}$ and $\mathrm{SW}$ groups $\left[F_{(6,81)}=4.91\right.$; $\mathrm{p}<0.001]$ and $\mathrm{W}$ group $\left[F_{(6,81)}=4.91 ; \mathrm{p}<0.05\right]$ (Fig. 1). Further, prenatally MA-treated mothers showed increased latency to return all pups to the nest relative to SA-treated dams $\left[F_{(2,81)}=4.01 ; \mathrm{p}<0.05\right]$. There were no significant differences in the latency to carry the first pup or to return the first pup to the nest. 


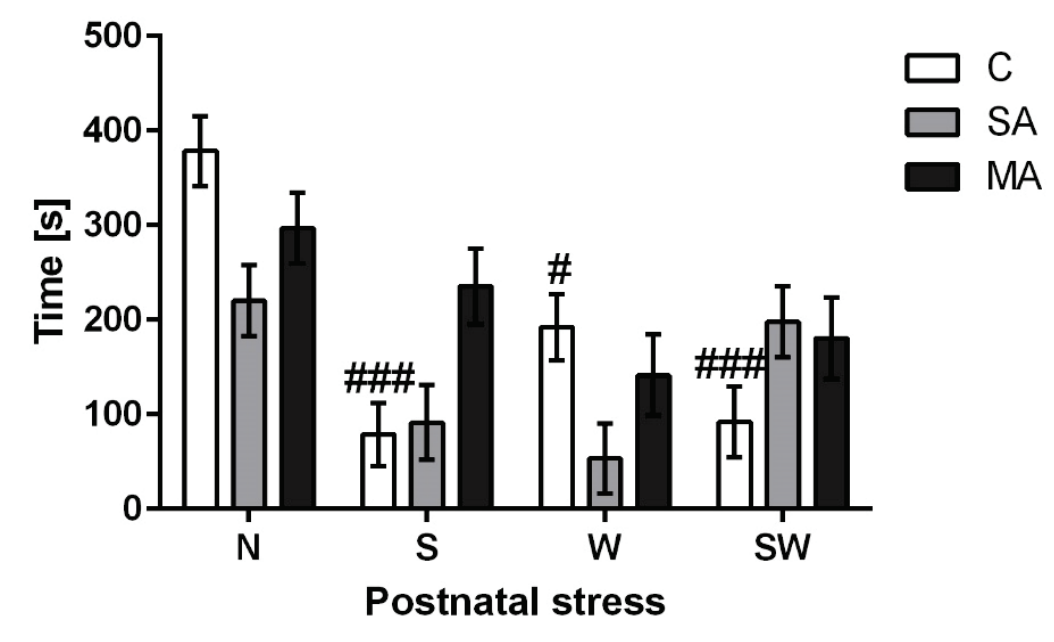

Fig. 1. Latency to carry all pups to the nest revealed significant differences between stressed dams (S-C, W-C, $\mathrm{SW}-\mathrm{C}$ ) and controls (N-C). Values are means \pm SEM. $\mathrm{C}=$ control; $\mathrm{SA}=$ saline; $\mathrm{MA}=$ methamphetamine; $\mathrm{N}=$ postnatally non-stressed group; $\mathrm{S}=$ maternal separation; $W=$ maternal cold-water stress; SW = combined stressor. $\quad \# p<0.05 ; \quad \# \# p<0.001$ significant difference among postnatally affected groups.

\section{Battery of tests of the pups' development Righting reflex on surface}

As shown in Figure 2, pups of prenatally MA-exposed mothers were slower to right than controls in the other groups during the first days of testing (PD 1). Specifically, in the postnatal non-stressed group $(\mathrm{N})$, pups of prenatally MA-exposed mothers $\left[F_{(10,450)}=1.57\right.$; $\mathrm{p}<0.05$ ] were slower to right than those in the $\mathrm{C}$ and $\mathrm{SA}$ groups. In group $\mathrm{S}$, the pups of the MA$\left[F_{(10,702)}=3.93 ; \quad \mathrm{p}<0.05\right]$ and $\mathrm{SA}$-exposed mothers $\left[F_{(10,702)}=3.93 ; \quad \mathrm{p}<0.01\right]$ were slower than controls. Similarly within $\mathrm{W}$ group, there were differences between pups of MA $\left[F_{(10,768)}=3.24 ; \mathrm{p}<0.01\right]$ and
SA-exposed mothers $\left[F_{(10,768)}=3.24 ; \mathrm{p}<0.05\right]$ compared to controls. Within the $\mathrm{SW}$ group, (i.e. combined stressors) pups of MA-exposed mothers $\left[F_{(10,630)}=2.26 ; \mathrm{p}<0.05\right]$ were slower than SA and $\mathrm{C}$ pups during the first two days of testing. In addition to the SW group, there were significant differences between pups of MA-exposed mothers $\left[F_{(10,630)}=2.26 ; \mathrm{p}<0.01\right]$ and controls on the second day of testing. As with the non-stressed group, pups of MA-exposed mothers were slower to right $\left[F_{(10,450)}=1.57 ; \mathrm{p}<0.05\right]$ than controls or the offspring of SA-exposed mothers. There was a decrease in the latency to right as the postnatal period progressed for all groups of animals.
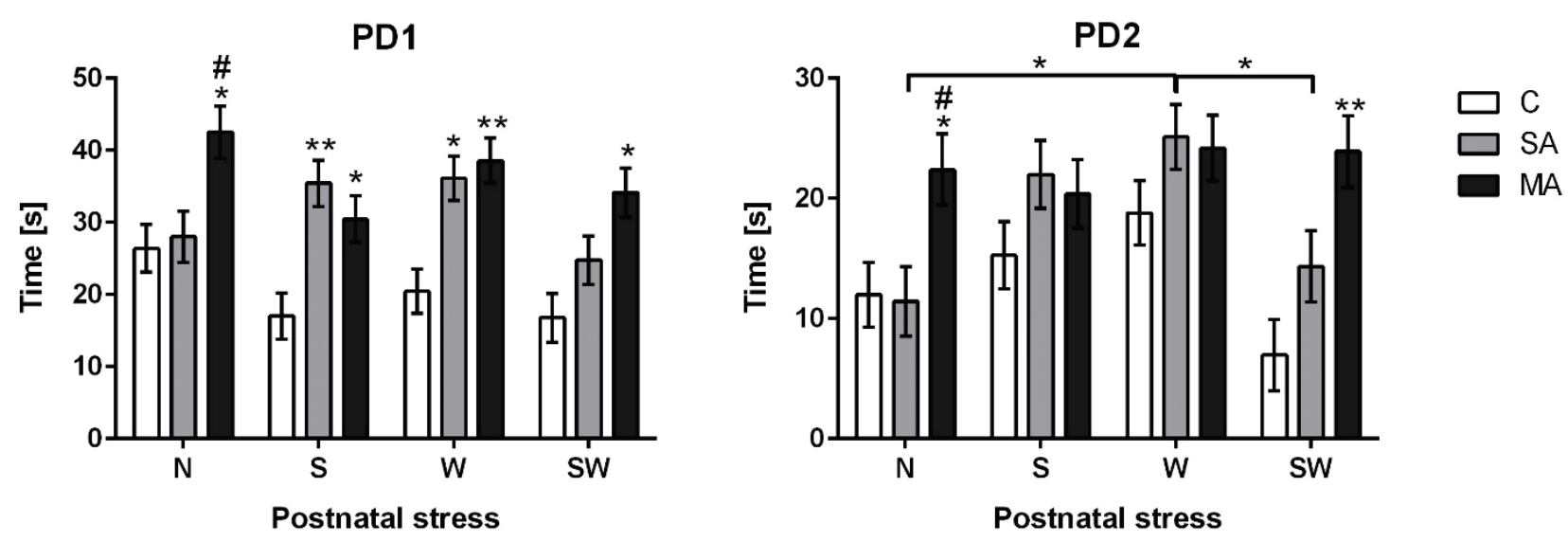

Fig. 2. Righting reflex on PD 1 and PD 2 with significant differences. Values are means $\pm S E M$. $C=$ control; SA $=$ saline; $\mathrm{MA}=$ methamphetamine; $\mathrm{N}=$ non-stressed controls; $\mathrm{S}=$ maternal separation; $\mathrm{W}=$ maternal cold-water stress; $\mathrm{SW}=$ combined stressor. ${ }^{*} p<0.05 ; * * p<0.01$ significant difference between affected groups and controls. ${ }^{*} p<0.05$ significant difference between the SA and MA group.

\section{Negative geotaxis}

There were significant differences between pups of MA-exposed mothers compared to the $\mathrm{SA}$ $\left[F_{(2,356)}=8.41 ; \mathrm{p}<0.001\right]$ and $\mathrm{C}\left[F_{(2,356)}=8.41 ; \mathrm{p}<0.01\right]$ groups, regardless of postnatal stress. Specifically, this effect was observed in prenatal MA females. The female-pups of MA-treated mothers were slower to manage the negative geotaxis test compared to femalepups from SA and $\mathrm{C}$ mothers. There were no significant differences among males. 


\section{Righting reflex in mid-air}

There were no significant differences among prenatally or postnatally groups in righting reflex in mid-air on PD 17. Additionally, no differences between males and females were observed.

\section{Bar-holding test}

There were no significant differences among all

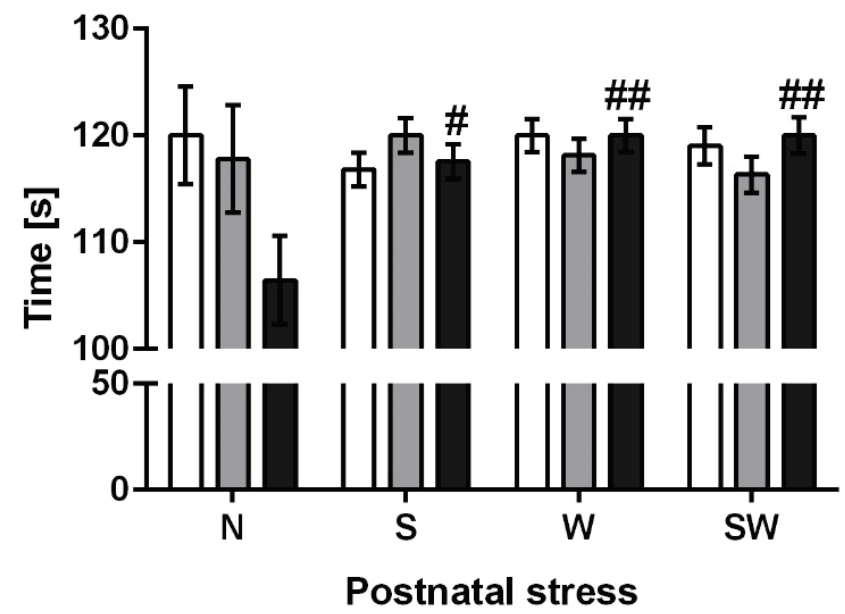

\section{Rotarod}

Pups of MA- and SA-exposed mothers spent less time $\left[F_{(2,383)}=5.01 ; \mathrm{p}<0.01\right]$ on the rotating cylinder compared to controls, regardless of postnatal stress or sex. All pups, regardless of maternal drug treatment, maternal stress exposure, or pup sex, improved with repeated trials.

\section{Discussion}

In the present study, MA- and SA-treated mothers showed no difference in gestation length. This result does not correspond with our previous results where MA-treated mothers had longer gestation periods compared to other groups (Šlamberová et al. 2005a). However, the data measured regarding the gestation period of MA-treated dams were very inconsistent. Some have reported shorter gestation periods in mothers with chronic administration of MA during pregnancy (Martin 1975, Martin et al. 1976). There was no decrease in weight gain during the gestation period and no differences in litter size in any of the tested groups, which is in agreement with our previous study (Šlamberová et al. 2006).

MA exposure during pregnancy induced lower birth weights compared to controls and SA-exposed pups. postnatally stressed groups with regard to the length of time pups remained on the bar, regardless of pup sex or prenatal drug treatment. However, in the first trial, pups of MA-exposed mothers from the non-stressed group N had significantly worse performances $\left[F_{(6,394)}=3.74\right.$; $\mathrm{p}<0.01]$ compared to pups of MA-exposed mothers with postnatal stress (S, W, SW), again, regardless of sex (Fig. 3).

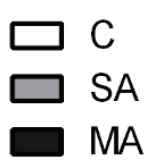

Fig. 3. Differences among MA-exposed postnatally stressed and non-stressed groups on the bar-holding test on the first trial. Values are means \pm SEM. $\mathrm{C}=$ control; $\mathrm{SA}=$ saline; $\mathrm{MA}=$ methamphetamine; $\mathrm{N}=$ non-stressed controls; $S=$ maternal separation; $\mathrm{W}=$ maternal cold-water stress; SW $=$ combined stressor. ${ }^{*} \mathrm{p}<0.05$; \#\# $p<0.05$ significant difference among postnatally affected groups.
This result supports several preclinical (Martin et al. 1976, Šlamberová et al. 2006, Malinová-Ševčíková et al. 2014) and clinical (Little et al. 1988, Smith et al. 2006) studies involving prenatal MA-exposure and the known anorectic effects of MA (Bittner et al. 1981). Something new and interesting in our study was with regard to weight gain of pups. Specifically, the postnatal S group gained significantly more weight than the others, regardless of prenatal treatment. One possible explanation could be that decreased plasma leptin levels in rats following maternal separation compared to controls (Salzmann et al. 2004, Walker et al. 2004, Smith et al. 2006, Holubová et al. 2016), which stimulates the appetite (Friedman 2011). This explanation is supported by maternal behavior in which stressed mothers breast-feed more in the passive position compared to controls, but spend the same amount of time as control in active position breast-feeding, meaning that, overall, the S-pups are breast-fed more often than controls (N-pups). This is in agreement with a study by Mesquita et al. (2007) where feeding time of pups was significantly increased in maternal separation groups, probably to compensate for long maternal absences (Mesquita et al. 2007). However, even though the $\mathrm{W}$ and $\mathrm{SW}$ mothers had frequent breast-feedings, their pups gained significantly less weight than the $\mathrm{S}$ group. Thus, it is suggested that 
maternal cold-water stress during the lactation period may have adverse effects of breast milk production. Since we did not test milk production and did not monitor food and water intake of pups individually, we will have to unravel this mystery in further experiments.

Increased passive nursing in stressed dams $(\mathrm{S}, \mathrm{W}, \mathrm{SW})$ correlates with increased maternal activity when stressed mothers were more in contact with their pups. It has been suggested that repeated maternal separation and presumptive lack of breast-milk in the $\mathrm{W}$ and SW groups also increase pup activity and causes them to nurse, regardless of prenatal treatment. MA-treated dams engaged in less licking and grooming their pups than the C and SA-treated dams, which is in agreement with our previous studies (Šlamberová et al. 2005a). Based on the results of the retrieval test, stressed controls (S-C, W-C, SW-C) displayed increased interest in their pups compared to the non-stressed group (N-C). Thus, MA as well as stress (SA) exposure during pregnancy can be decisive factors in impairment of maternal behavior during the lactation period (Šlamberová et al. 2005a). Furthermore, MA-treated mothers were significantly slower to carry pups back to the nest than the SA-treated groups, which supports the idea that MA-exposure leads to a decline in maternal care and less interest in offsprings (Šlamberová et al. 2005a, Šlamberová et al. 2005b).

Previous studies have demonstrated the harmful effects of prenatal MA exposure on sensorimotor development of affected progeny (Acuff-Smith et al. 1996, Šlamberová et al. 2006, Malinová-Ševčíková et al. 2014). In our study, pups of MA-exposed mothers were slower to right during testing of the righting reflex on a surface. Furthermore, prenatal MA exposure has been observed to adversely affect performance on the negative geotaxis and rotarod tests (Hrubá et al. 2009) and the bar-holding test (Šlamberová et al. 2006). The present study was designed to determine whether various perinatal stressors play an important role in the development of affected pups. While maternal MA-exposure delayed the righting reflex regardless of maternal postnatal stressors during the first postnatal days, prenatal stress (i.e. the SA group) had harmful effects only in the postnatally stressed groups (S, W). Thus, it seems that postnatal stressors magnify the negative effect of repeated injections during pregnancy. Other studies have also demonstrated that stress during pregnancy induced long-term impairment of stress responsiveness in adult progeny (Peters 1986,
Šlamberová et al. 2002), possibly due to impaired coping with stressful situations (Weinstock et al. 1997). The impairing effect of prenatal stressors, regardless of postnatal stress, was also observed during rotarod performance on PD 23, showing long-lasting impairment of dynamic postural reactions. This result is consistent with our previous studies (Šlamberová et al. 2006). Interestingly, prenatally MA-exposed pups that were postnatally stressed often had better results on the bar-holding test than the non-stressed group $(\mathrm{N})$. One possible explanation could be that pups exposed to stress in early life display decreased movement due to increased anxiety-like behavior and decreased exploratory activities (Aisa et al. 2007, Yang et al. 2017), which are mediated by the HPA axis and modulated by limbic structures like the hippocampus, prefrontal cortex, and amygdala (Leon Rodriguez and Duenas 2013). An examination of anxietylike behavior and exploratory activities in postnatally stressed progeny are planned in our future experiments. Negative geotaxis on PD 9 showed no differences among postnatally stressed groups, which is consistent with a study by Mesquita et al. (2007), where S-N differences were only maintain until PD 7. The same study might also explain why there were no differences in the mid-air righting reflex test on PD 17, i.e. the effect of neonatal stress disappears by PD 12 (Mesquita et al. 2007).

The present study suggests that a combination of maternal postnatal stressors with prenatal stress and drug exposure has detrimental effects on maternal behavior as well as on the sensorimotor development of their pups. However, MA exposure during pregnancy seems to be the decisive factor for those impairments. To our knowledge, there are no studies examining this combination of stressors on maternal behavior and pup development. Since drug-abusing mothers can be less fastidious in their prenatal as well as postnatal care, this could lead to psychological deprivation of their children (Rokyta et al. 2008, Vavř́nková et al. 2001), and as such this area of investigation deserves further attention. Therefore, we plan future studies to investigate the effect of perinatal stressors on behavior, cognition, and social interaction in the adult progeny of prenatally MA-exposed mothers.

\section{Conflict of Interest}

There is no conflict of interest.

\section{Acknowledgements}

This work was supported by research program 
PROGRES Q 35, projects GAUK 850317, and 260388/SVV/2017 from Charles University. The authors express their appreciation to Thomas Ownsby Secrest, M.Sc. for critical reading and editing of the manuscript. The procedures for animal experimentation utilized in this study was reviewed and approved by the Institutional
Animal Care and Use Committee and were in agreement with the Czech Government Requirements under the Policy of Humane Care of Laboratory Animals (No. 246/1992) and with subsequent regulations of the Ministry of Agriculture of the Czech Republic (No. 311/1997).

\section{References}

ACUFF-SMITH KD, SCHILLING MA, FISHER JE, VORHEES CV: Stage-specific effects of prenatal d-methamphetamine exposure on behavioral and eye development in rats. Neurotoxicol Teratol 18: 199-215, 1996.

AISA B, TORDERA R, LASHERAS B, DEL RIO J, RAMIREZ MJ: Cognitive impairment associated to HPA axis hyperactivity after maternal separation in rats. Psychoneuroendocrinology 32: 256-266, 2007.

ALTMAN J, SUDARSHAN K: Postnatal development of locomotion in the laboratory rat. Anim Behav 23: 896-920, 1975.

BITTNER SE, WAGNER GC, AIGNER TG, SEIDEN LS: Effects of a high-dose treatment of methamphetamine on caudate dopamine and anorexia in rats. Pharmacol Biochem Behav 14: 481-486, 1981.

CHARIL A, LAPLANTE DP, VAILLANCOURT C, KING S: Prenatal stress and brain development. Brain Res Rev 65: 56-79, 2010.

DANIELS WM, PIETERSEN CY, CARSTENS ME, STEIN DJ: Maternal separation in rats leads to anxiety-like behavior and a blunted ACTH response and altered neurotransmitter levels in response to a subsequent stressor. Metab Brain Dis 19: 3-14, 2004.

DRAGO F, Di LEO F, GIARDINA L: Prenatal stress induces body weight deficit and behavioural alterations in rats: the effect of diazepam. Eur Neuropsychopharmacol 9: 239-245, 1999.

FRIEDMAN JM: Leptin and the regulation of body weigh. Keio J Med 60: 1-9, 2011.

GRISSOM N, BHATNAGAR S: Habituation to repeated stress: get used to it. Neurobiol Learn Mem 92: 215-224, 2009.

HOLUBOVÁ A, ŠTOFKOVÁ A, JURČOVIČOVÁ J, ŠLAMBEROVÁ R: The effect of neonatal maternal stress on plasma levels of adrenocorticotropic hormone, corticosterone, leptin, and ghrelin in adult male rats exposed to acute heterotypic stressor. Physiol Res 65 (Suppl 5): S557-S566, 2016.

HRUBÁ L, SCHUTOVÁ B, ŠLAMBEROVÁ R, POMETLOVÁ M, ROKYTA R: Effect of methamphetamine exposure and cross-fostering on sensorimotor development of male and female rat pups. Dev Psychobiol 51: 73-83, 2009.

KISH SJ: Pharmacologic mechanisms of crystal meth. CMAJ 178: 1679-1682, 2008.

LADD CO, OWENS MJ, NEMEROFF CB: Persistent changes in corticotropin-releasing factor neuronal systems induced by maternal deprivation. Endocrinology 137: 1212-1218, 1996.

LAJUD N, ROQUE A, CAJERO M, GUTIERREZ-OSPINA G, TORNER L: Periodic maternal separation decreases hippocampal neurogenesis without affecting basal corticosterone during the stress hyporesponsive period, but alters HPA axis and coping behavior in adulthood. Psychoneuroendocrinology 37: 410-420, 2012.

LARSSON G, ERIKSSON M, ZETTERSTROM R: Amphetamine addiction and pregnancy. Psycho-social and medical aspects. Acta Psychiatr Scand 60: 334-346, 1979.

LEON RODRIGUEZ DA, DUENAS Z: Maternal separation during breastfeeding induces gender-dependent changes in anxiety and the GABA-A receptor alpha-subunit in adult Wistar rats. PLoS One 8: e68010, 2013.

LILES BD, NEWMAN E, LAGASSE LL, DERAUF C, SHAH R, SMITH LM, ARRIA AM, HUESTIS MA, HANING W, STRAUSS A, ET AL.: Perceived child behavior problems, parenting stress, and maternal depressive symptoms among prenatal methamphetamine users. Child Psychiatry Hum Dev 43: 943-957, 2012.

LITTLE BB, SNELL LM, GILSTRAP LC 3RD: Methamphetamine abuse during pregnancy: outcome and fetal effects. Obstet Gynecol 72: 541-544, 1988. 
MALINOVÁ-ŠEVČÍKOVÁ M, HREBÍČKOVÁ I, MACÚCHOVÁ E, NOVÁ E, POMETLOVÁ M, ŠLAMBEROVÁ R: Differences in maternal behavior and development of their pups depend on the time of methamphetamine exposure during gestation period. Physiol Res 63 (Suppl 4): S559-S572, 2014.

MARAIS L, VAN RENSBURG SJ, VAN ZYL JM, STEIN DJ, DANIELS WM: Maternal separation of rat pups increases the risk of developing depressive-like behavior after subsequent chronic stress by altering corticosterone and neurotrophin levels in the hippocampus. Neurosci Res 61: 106-112, 2008.

MARTIN JC: Effects on offspring of chronic maternal methamphetamine exposure. Dev Psychobiol 8: 397-404, 1975.

MARTIN JC, MARTIN DC, RADOW B, SIGMAN G: Growth, development and activity in rat offspring following maternal drug exposure. Exp Aging Res 2: 235-251, 1976.

MARWICK C: NIDA seeking data on effect of fetal exposure to methamphetamine. JAMA 283: 2225-2226, 2000.

MESQUITA AR, PEGO JM, SUMMAVIELlE T, MACIEL P, ALMEIDA OF, SOUSA N: Neurodevelopment milestone abnormalities in rats exposed to stress in early life. Neuroscience 147: 1022-1033, 2007.

ORO AS, DIXON SD: Perinatal cocaine and methamphetamine exposure: maternal and neonatal correlates. $J$ Pediatr 111: 571-578, 1987.

PETERS DA: Prenatal stress increases the behavioral response to serotonin agonists and alters open field behavior in the rat. Pharmacol Biochem Behav 25: 873-877, 1986.

PLOTSKY PM, THRIVIKRAMAN KV, NEMEROFF CB, CALDJI C, SHARMA S, MEANEY MJ: Long-term consequences of neonatal rearing on central corticotropin-releasing factor systems in adult male rat offspring. Neuropsychopharmacology 30: 2192-2204, 2005.

POMETLOVÁ M, HRUBÁ L, ŠLAMBEROVÁ R, ROKYTA R: Cross-fostering effect on postnatal development of rat pups exposed to methamphetamine during gestation and preweaning periods. Int J Dev Neurosci 27: 149-155, 2009.

RAMBOUSEK L, KAČER P, SYSLOVÁ K, BUMBA J, BUBENÍKOVÁ-VALEŠOVÁ V, ŠLAMBEROVÁ R: Sex differences in methamphetamine pharmacokinetics in adult rats and its transfer to pups through the placental membrane and breast milk. Drug Alcohol Depend 139: 138-144, 2014.

ROKYTA R, YAMAMOTOVÁ A, ŠLAMBEROVÁ R, FRANĚK M, VACULÍN S, HRUBÁ L, SCHUTOVÁ B, POMETLOVÁ M: Prenatal and perinatal factors influencing nociception, addiction and behavior during ontogenetic development. Physiol Res 57 (Suppl 3): S79-S88, 2008.

SALZMANN C, OTIS M, LONG H, ROBERGE C, GALLO-PAYET N, WALKER CD: Inhibition of steroidogenic response to adrenocorticotropin by leptin: implications for the adrenal response to maternal separation in neonatal rats. Endocrinology 145: 1810-1822, 2004.

SAPOLSKY RM, MEANEY MJ: Maturation of the adrenocortical stress response: neuroendocrine control mechanisms and the stress hyporesponsive period. Brain Res 396: 64-76, 1986.

ŠLAMBEROVÁ R: Drugs in pregnancy: the effects on mother and her progeny. Physiol Res 61 (Suppl 1): S123-S135, 2012.

ŠLAMBEROVÁ R, CHAROUSOVÁ P, POMETLOVÁ M: Methamphetamine administration during gestation impairs maternal behavior. Dev Psychobiol 46: 57-65, 2005a.

ŠLAMBEROVÁ R, CHAROUSOVÁ P, POMETLOVÁ M: Maternal behavior is impaired by methamphetamine administered during pre-mating, gestation and lactation. Reprod Toxicol 20: 103-110, $2005 \mathrm{~b}$.

ŠLAMBEROVÁ R, POMETLOVÁ M, CHAROUSOVÁ P: Postnatal development of rat pups is altered by prenatal methamphetamine exposure. Prog Neuropsychopharmacol Biol Psychiatry 30: 82-88, 2006.

ŠLAMBEROVÁ R, SCHINDLER CJ, VATHY I: Impact of maternal morphine and saline injections on behavioral responses to a cold water stressor in adult male and female progeny. Physiol Behav 75: 723-732, 2002.

SMITH LM, DIAZ S, LAGASSE LL, WOULDES T, DERAUF C, NEWMAN E, ARRIA A, HUESTIS MA, HANING W, STRAUSS A, ET AL.: Developmental and behavioral consequences of prenatal methamphetamine exposure: A review of the Infant Development, Environment, and Lifestyle (IDEAL) study. Neurotoxicol Teratol 51: 35-44, 2015.

SMITH LM, LAGASSE LL, DERAUF C, GRANT P, SHAH R, ARRIA A, HUESTIS M, HANING W, STRAUSS A, DELLA GROTTA S, ET AL.: The infant development, environment, and lifestyle study: effects of prenatal methamphetamine exposure, polydrug exposure, and poverty on intrauterine growth. Pediatrics 118: 1149-1156, 2006. 
VAVŘÍNKOVÁ B, BINDER T, ZIVNY J: Characteristics of a population of drug dependent pregnant women in the Czech Republic. (In Czech) Ceska Gynekol 66: 285-291, 2001.

WALKER CD, SALZMANN C, LONG H, OTIS M, ROBERGE C, GALLO-PAYET N: Direct inhibitory effects of leptin on the neonatal adrenal and potential consequences for brain glucocorticoid feedback. Endocr Res 30: 837-844, 2004.

WELBERG LA, THRIVIKRAMAN KV, PLOTSKY PM: Chronic maternal stress inhibits the capacity to up-regulate placental 11 beta-hydroxysteroid dehydrogenase type 2 activity. $J$ Endocrinol 186: R7-R12, 2005.

YANG Y, CHENG Z, TANG H, JIAO H, SUN X, CUI Q, LUO F, PAN H, MA C, LI B: Neonatal maternal separation impairs prefrontal cortical myelination and cognitive functions in rats through activation of Wnt signaling. Cereb Cortex 27: 2871-2884, 2017. 